\title{
What's in the name?
}

\section{John A. Campbell}

Artificial Intelligence: The Very Idea. By John Haugeland.

MIT Press:1985. Pp.289. \$14.95, £14.95

AmONG scientific subjects, artificial intelligence has one unique distinction: it has been the victim of its own name. Because the name comes straight from everyday language, too many people have found futuristic messages in it merely through the associations that occur when "intelligence" and "artificial" are coupled together. The results have included sciencefiction interpretations and unreasonable expectations of the subject, and confusion of what has been achieved with what has not. Quite rightly, some of the founding fathers have conceded, at least in private, that not enough care was taken 30 years ago to find a label free of loaded words.

Among specialists, there are at least three different definitions of what artificial intelligence involves. One is the study of human intelligence through the use of methods and metaphors depending essentially on computers and computation; this admits both a middle-of-theroad view, in which the definition means neither more nor less than what it says, and a man-

But is there any future in Artificial lntelligence, Baron Frankenstein?
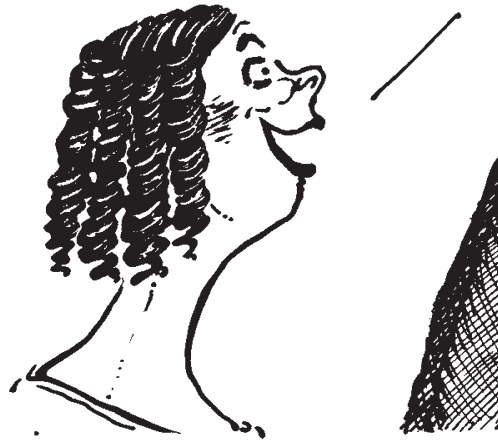

sopher. On previous evidence, such a vantage point has been no guarantee of successful writing on artificial intelligence - indeed, it seems rather to have guaranteed frequent encounters with the technical and even philosophical banana-skins that litter the field - but Haugeland arrives almost undamaged at the finishing line in this obstacle course.

His central concern is to explore the connection between intelligence and the idea of thought as a formal or at least rational manipulation of symbols. A first chapter on the evolution of philosophical views of "mind" is therefore followed by straightforward description of some of the symbol-manipulating systems, such as Turing machines, that have had the most influence on theoretical computer science and computability. There is also a simple account of models of computation, which makes the point that today's standard computer architecture, not well adapted to any of the definitions of artificial intelligence, is easy to replace with alternative designs that perform better in simulations. This is not news to specialists in advanced computing and to people familiar with the Japanese Fifth Generation plan, but it deserves repetition for a general audience.
As a basis for his substantive arguments, Haugeland's tour of the history of theoretical computer science is less satisfactory than his discussion of issues where he is surer of his philosophical ground. In the historical sections, for example, Alonzo Church is short-changed (by omission) on two counts and possibly three, with partial compensation for this Churchless picture only in the footnotes (where there is still confusion about the difference between Turing's "thesis" and Church's thesis, among other lesser things). Computer scientists may have the sense of seeing their subject through frosted glass here, but at least the author's heart is in the right place. And there is plenty of nourishment in the footnotes in general; collected conveniently at the end of the book, they can be sampled like a chariot of desserts.

The main value of the book to both specialists and non-specialists lies in the attention given to the two principal difficulties of current research in artificial intelligence. These are the frame problem, which is the problem of knowing how to link an item of information efficiently with all the other items that may be needed to establish the context in which its meaning may be determined properly, and the problem of how to assign and manipulate meanings (semantics) of expressions whose rules for structural (syntax) transformations are spelled out in formal symbol-manipulating systems. The problems themselves are well described, so that a general reader can appreciate the irritation that they cause to researchers, especially in speculation on how the human brain solves or avoids them. Haugeland weighs the balance of impressions justly: he is a pessimist rather than an optimist, but admits that, on the evidence, the basic questions of the achievability of "artificial intelligence" remain open.

While contexts and meanings may complicate work in artificial intelligence, there are both possible and desirable ways of reducing the complexity. On the "possible" level, problems of how to represent meaning may become much more tractable if the basic semantic operation usea in a formal computational system, or even a brain, is nothing more than a two-way choice or distinction between alternatives or stimuli. And artificial-intelligence research can desire nothing better of its spectators than that they agree to replace the subject's label with one that calls up no wild associations. "AI" for "artificial intelligence", say? The very idea!

John A. Campbell is Professor in the Department of Computer Science, University of Exeter, Exeter EX4 4PT, UK. past. Haugeland's book does not fill this gap. Instead, it joins the queue (or, 